\title{
The Present and Future of the Prominence Observations at Valašské Meziríící Astronomical Observatory
}

\author{
L. Lenža and D. Dokoupilová \\ Astronomical Observatory, Vsetínská 78, 75701 Valašské Meziř́čí, Czech \\ Republic
}

\begin{abstract}
This observatory is not a large institution, though we do carry out long term photographic monitoring of prominences. Our intention is to inform everybody about our observation programmes, the quality of our observations, our archive and the possibilities for its use.

We present examples of our photographic observations, an electronic archive of observation intervals and events, a prominence catalogue, and we discuss possible future co-operation.
\end{abstract}

\section{Introduction}

The observatory at Valašské Meziříčí was founded in 1955 and in the year 1964 the building for special observations was opened. One part of our work is the photographic observation of the Sun, showing its activity. We photograph the whole solar disc (overview photos), with details of the photosphere (sunspot groups) and solar prominences. All of the observations are now in our archive.

\section{Solar Observations}

We have been making photographic observations of the Sun since 1957, when our archive of overview photos started (October 4,1957) and now there are over 9425 photos. The images are being made by a Zeiss $\mathrm{E} 120 / 1920 \mathrm{~mm}$ refractor, where the diameter of the solar disc in negative is $66 \mathrm{~mm}-$ see Figure 1 . We make photographs using planfilm FOMA Repro 05.

Photographs of sunspot groups have been made since 1981 (April 7, 1981) by a Zeiss $200 / 3000 \mathrm{~mm}$ refractor (see Figure 2). We are using negative material ORWO MA8. One millimetre on the negative is $7.5 \mathrm{arc}$ sec. The number of photographic observations is now more than 1750 series of pictures.

\section{Prominence Observations}

Prominence observations are done with an $\mathrm{H} \alpha$ coronograph with a Zeiss $\mathrm{E}$ $150 / 1950 \mathrm{~mm}$ objective with Solc filter (passband $0.5 \mathrm{~nm}$ ) and KODAK 2415 Technical Pan film or KODAK SO115 film.

In the period between June 15, 1970 and November 8, 1983 the observations were very irregular, so we have only a few tens of series of observations. Regular 


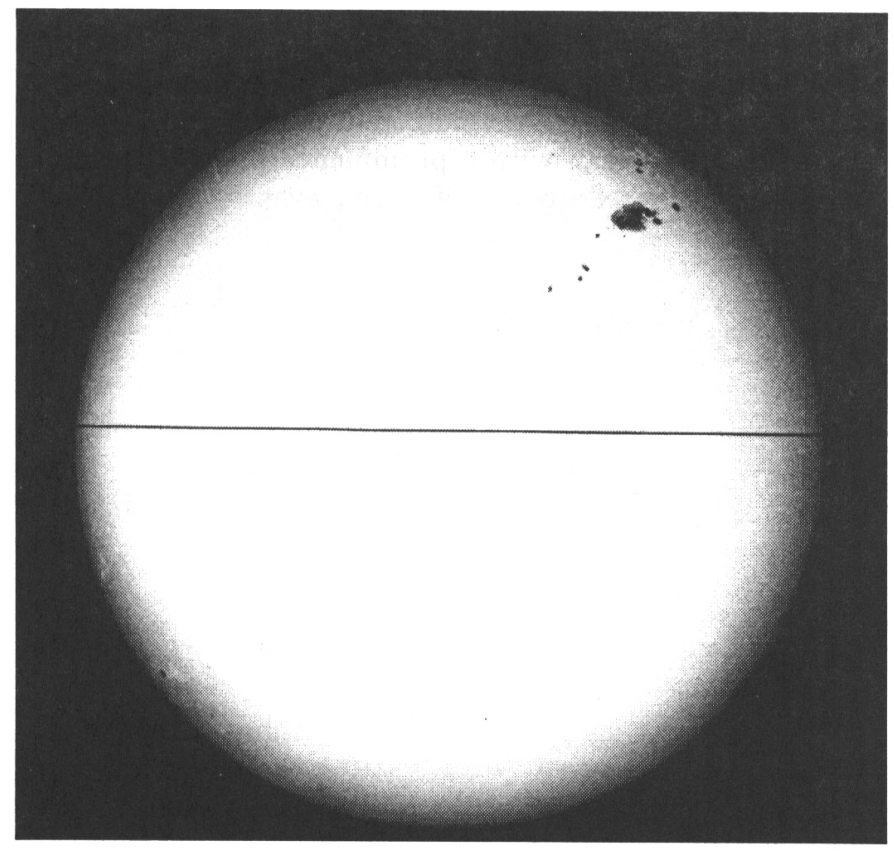

Figure 1. Date: September 27, 1991; Time: 14:28 UT; Device: Zeiss E 130/1930 refractor; Material: ORWO DU3; Observer: Libor Lenža.

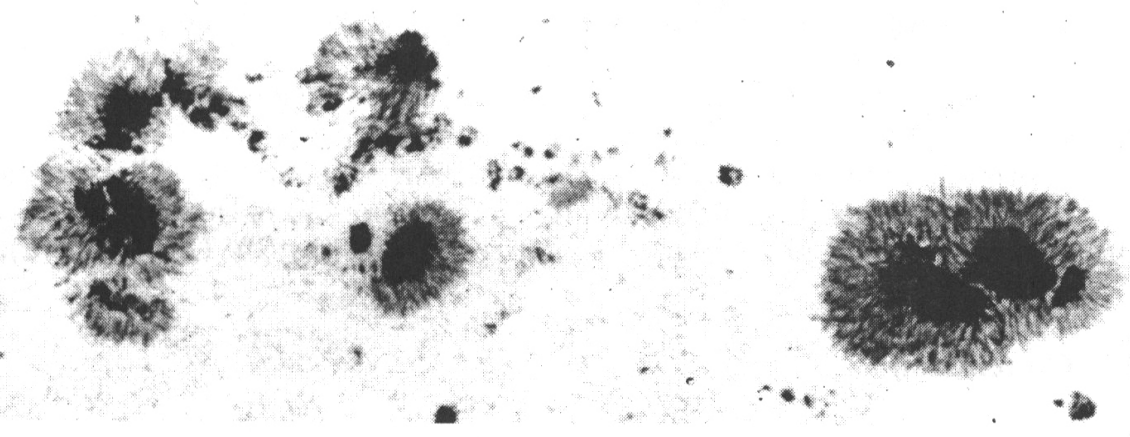

Figure 2. Date: July 4, 1992; Time: 07:52 UT; Device: Zeiss AS 200/3000 refractor; Material: ORWO MA8; Observer: Libor Lenža. 
observations began on July 24, 1984 and have continued until today. Since 1991 we have done our observations more intensively. From that period we have over 850 series of pictures. And in 1993 we started to send overview maps to the WDC-A in Boulder.

In May 1991 we started non-periodic photographic observations of active prominences. In 1992 we began with a prominence photographic patrol. Up to the present we have registered about 160 active events.

\section{The Quality of Observations}

The observation conditions are worst in the winter and best in the summer months. The quality of our images is represented in the pictures shown in Figure 3. The angular resolution reaches about 2 arc sec. Generally we can say that these images are applicable for studying dynamics and the morphology of events.

\section{The Archive and its Availability}

All the negatives of photographic observations are signed with the necessary data and centrally archived. At present we are putting the archive into electronic files so it could be available to anyone interested in it. Those who are interested in it will then automatically receive updates.

In the first archive is information about observing the photosphere (detail and overview image). This archive provides information on when the observation was done and what its quality was. In case you would like to have any of our images, you can write to us with a particular request based on our electronic archive. At present this archive contains data for the years 1989-1996.

Prominence observations are archived in the same way. Presently it contains data only for the year 1993.

For each observation day a drawn map is available which is used for statistical processing. They can also be used for rating the co-ordinates, altitudes and other statistical parameters of each prominence. Data for the year 1993 are listed in a catalogue, which is identical to the catalogue produced by the Lomnický Štít Observatory in the Slovak Republic.

Information about active events is being archived separately. This includes information about observing intervals. If you are interested in these data, we are able to send standard photographs or digitized images (by TV CCD camera).

\section{Conclusion}

At present we are putting the basic information from the archive into electronic files for each type of observation. We are also completing the prominence catalogue.

We are now testing our TV CCD system for observing prominences. We would like to co-operate with other observatories. Our observations and data are available to any astronomer. 
Acknowledgments. We thank everybody who participated in producing our archive of solar observations.
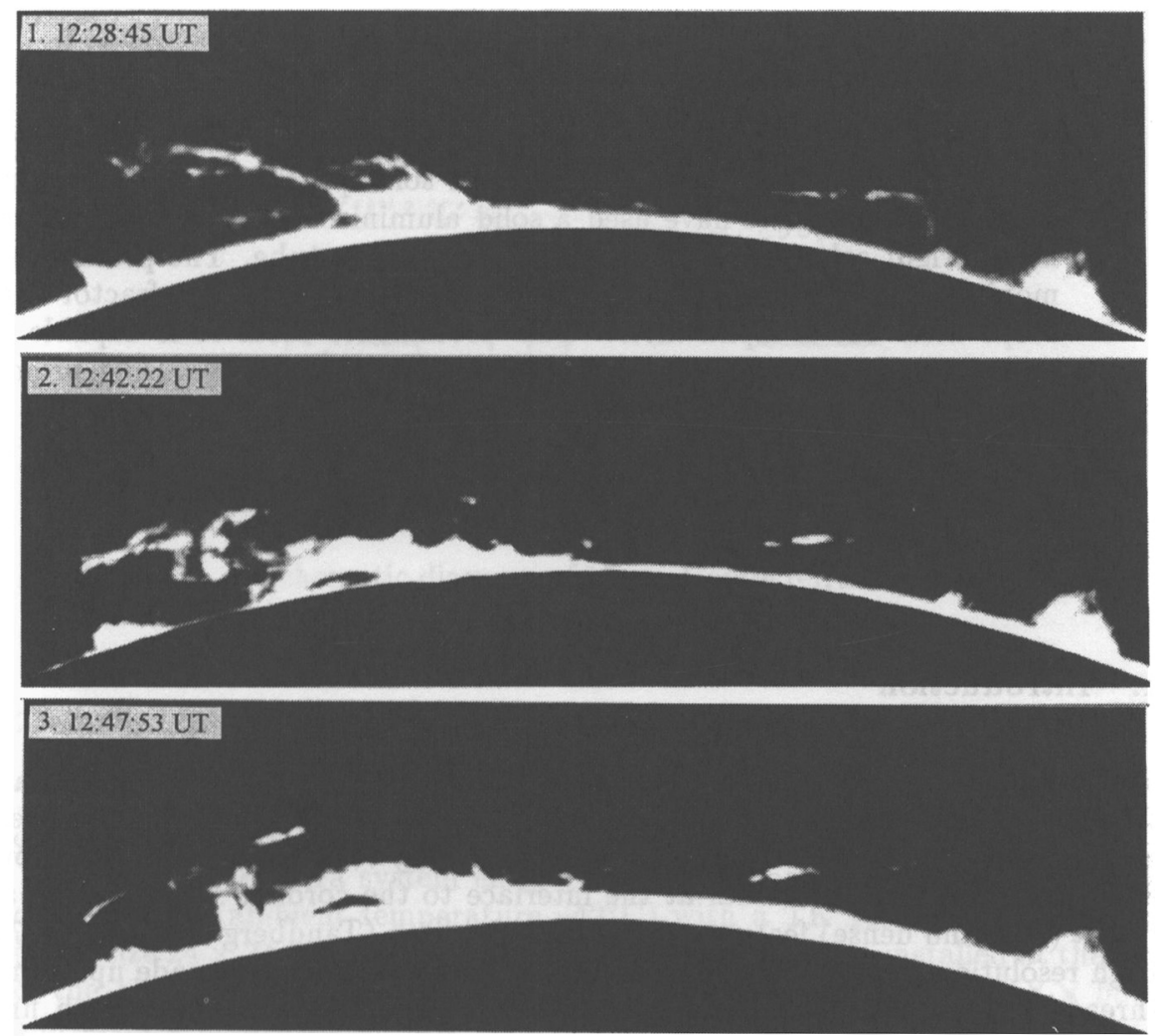

Figure 3. Date: March 5, 1997; Device: $\mathrm{H} \alpha$ coronograph with Zeiss E 150/1950 mm objective with Solc filter (passband 0.5 nm); Position: N14E; Material: KODAK SO115; Observer: Ladislav Šmelcer. 